\title{
Design and Simulation Study on Automobile Parts Production Line ZhaoMing Chen ${ }^{1, a}$, Ying Zhao ${ }^{1, b}, Z^{2} Y \mathrm{Xu}^{1, \mathrm{c}}$ \\ ${ }^{1}$ Chongqing Institute of Green and Intelligent Technology, Chinese Academy of Sciences, 400714, China \\ azhaomingc_sc@163.com, bhaoying@cigit.ac.cn, ‘xzy@cigit.ac.cn
}

Keywords: production line, simulation model, bottleneck, lot sizing, plant simulation.

\begin{abstract}
With the need of bolt parts automatically processing requirements for a manufacture company, an automatic production line of this parts was designed, also simulated and optimized. Firstly, on the basis of analyzing the process characteristics of bolt, the process route of it was established by considering the balance of the production line and the distribution of working procedure; Then, the automatic production line simulation model was built by using the object oriented modeling method, meanwhile the line was emulated in the discrete system simulation software Plant Simulation, the blocking problem in the productive process was improved and optimized from the aspects of adjusting the number of key equipment, and improving the process route. The experiment results show that the improved production line running reliably, the balance of the production line and production efficiency are improved significantly. It will reduce the planning and engineering costs, and provide technical support for the production line construction.
\end{abstract}

\section{Introduction}

With the changing of the global economic situation, the manufacturing enterprises confronted with severe challenges such as the market demand of the products was diversified and personalized, the product updating speed was accelerated, and the product life cycle was shortened [1-3]. So, under the premise of ensuring product quality, enterprises must accurately respond to the market demands by constantly optimizing the production mode, improving production efficiency, and reducing production cycle. Nowadays, under the lean production mode, many automobile manufacturing enterprises have realized that the planning and layout of a new production line directly determines the product quality, production efficiency and economic benefit of the enterprise. Therefore, the production line design is attached great importance [4-5]. It was very difficult to achieve the expected effect of the design, implementation and control of a production line by using the traditional manual design method [6-7]. According to reports, many have been running complex manufacturing systems (especially FMS) about 80\% [8-9] in foreign countries were not fully meet the design requirements. Computer aided design method based on virtual manufacturing technology has been widely used in the design, operation and optimization of the manufacturing system. The Plant Simulation software was used to model and simulate the designed production line to find out possible problems in the planning, and to find the optimal design by modifying and adjusting the parameters, which could reduce the capital investment, reduce the running cost and improve the production efficiency. Finally, it could provide a solid foundation for the long-term high-efficiency operation of the production line.

\section{Analysis of the production demand and process characteristics of bolt}

\subsection{Production demand of bolt}

A manufacturing enterprise needed to expand the production scale of bolt to meet the market demand, so it was necessary to build a new production line to adapt the new production plan. The designed annual production capacity was 1 million, the monthly work time was 25 days, 20 hours a day, with two classes, the rest time of each class was $0.5 \mathrm{~h}$, equipment operation rate was $90 \%$, and the key size $\mathrm{CPK} \geqslant 1.33$. 


\subsection{Process characteristics analysis of bolt}

The engineering drawing of bolt was shown in figure1. The surfaces that needed to be processed include: turning the outer circles and the inner holes, drilling the radial holes and grinding the important working surfaces. The Concentricity and perpendicularity requirements of inner holes' surfaces were high, the circlip groove had narrow width and high precision requirement. Therefore, it was an important issue in processing that how to ensure the geometrical precision of each surface. Considering the principle of working procedure and the balance of production line, the process route was formulated as follows: (1)turning the end face and outer circles, turning the inner hole $\Phi$ 12 and screw thread; (2)turning the other end face and the rest outer circles, turning the inner holes, cutting the retainer ring groove, milling the semicircle groove; (3)drilling two rounds of radial holes Ф3.2, with chamfer; (4)honing inside hole Ф34H6;(5)Laser Marking.
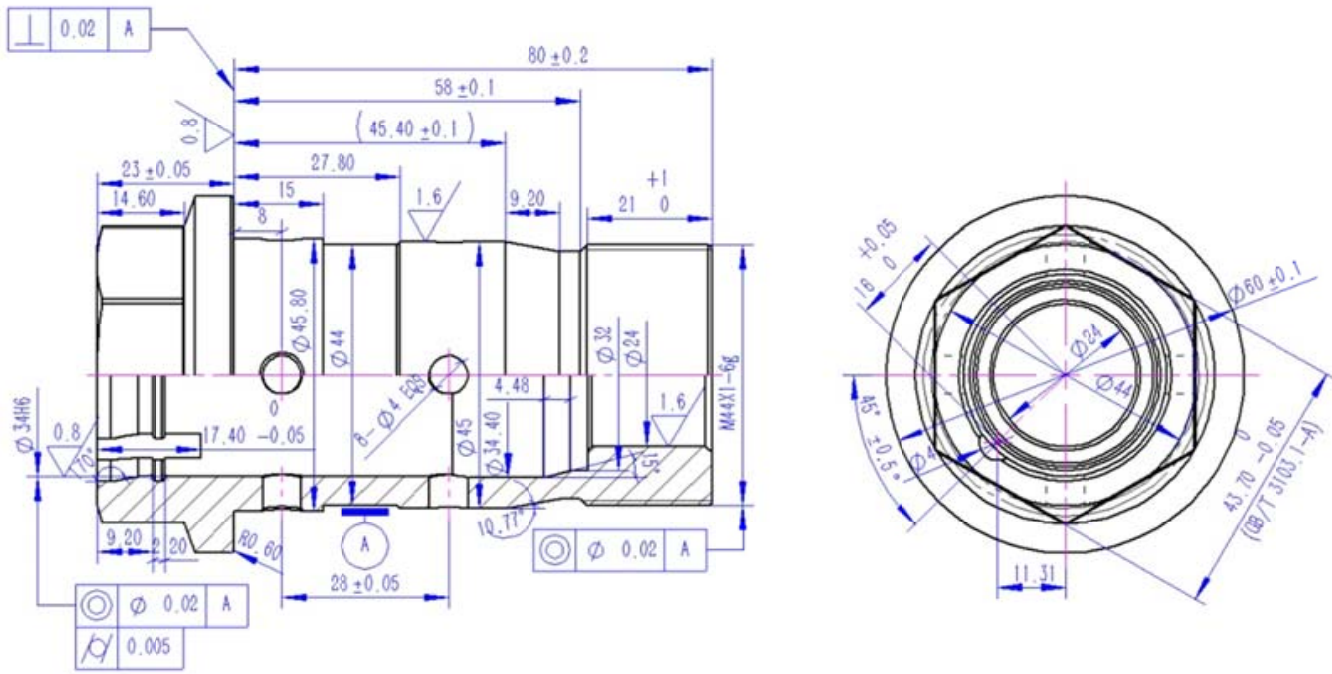

Fig. 1 bolt engineering drawing

According to the bolt processing route, the selected main processing equipment were as follows: KIT450 CNC lathe 4sets; I-CUT380TI drilling center 2sets; RC06 honing machine 1set; HM20 laser marking machine 1 set. The processing equipment combined with multi-joint robots and load-unload devices to form a production unit, which can achieve the production of several types of bolt, the processing layout was shown in figure 2 .

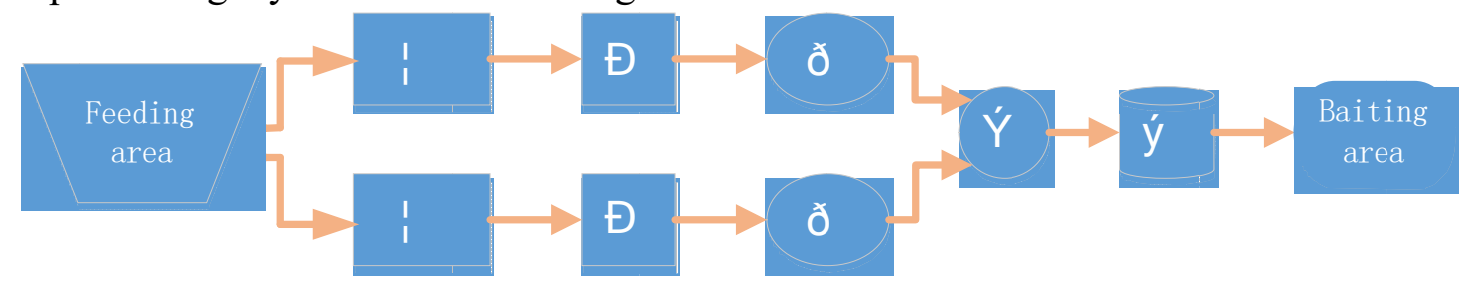

Fig. 2 bolt processing layout diagram

\section{The establishment and simulation analysis of production line model}

\subsection{Plant Simulation introduction}

Plant Simulation was developed by Tecnomatix company for production system, production process and logistics system modeling and simulation, which had a graphical, integrated, intuitive user environment[10-12]; It was easy to understand by fully object-oriented, hierarchical modeling process; also it had good compatibility, could provide various types of external interface, such as ASCII, SQL, DDC, OBDC, Word, Excel, etc.; Using the embedded SimTalk programming language, users could make detail control of the model. Meanwhile, users could analyze and 
optimize the production system indexes, such as production layout, resource utilization, logistics efficiency, wip level, workers load balance, etc., and rapid response to production decisions and carry out continuous improvement, finally, design a good production line.

\subsection{Simulation condition hypothesis}

Because of some uncontrollable factors in the actual production, logistics situation in discrete production workshop was also more complex, so the following assumptions were made to insure modeling the production line simulation model smoothly:

(1) spare parts supplied sufficiently, there was no shortage of material phenomenon;

(2) the preparation time of all equipment was 0 , bolts processing in accordance with the process priority, and no reflow phenomenon;

(3) equipment failure rate in the process of production was 0 ;

(4) skill level of all workers were the same, and personnel arrangement meet the processing requirements;

(5) no defective goods.

\subsection{Production line simulation model}

In Plant Simulation software singleproc module was used to represent the machine tool, buffer module was used to express the buffer, entity module was used to express bolt, chart module was used to analysis equipment utilization and Report module was used to analysis the production line bottleneck. At the same time, according to the processing schedule of bolt (see table1), the corresponding simulation settings of the model could be set up. The production line simulation model was established as shown in figure3.

Table 1 processing schedule

\begin{tabular}{|c|c|c|c|}
\hline production processes & equipment & numbers & processing time (s) \\
\hline OP10 & KIT450 CNC lathe & 2 & 20.4 \\
\hline OP20 & KIT450 CNC lathe & 2 & 29.4 \\
\hline OP30 & I-CUT380TI drilling center & 2 & 36.6 \\
\hline OP40 & RC06 honing machine & 1 & 15 \\
\hline OP50 & HM20 laser marking machine & 1 & 19 \\
\hline
\end{tabular}

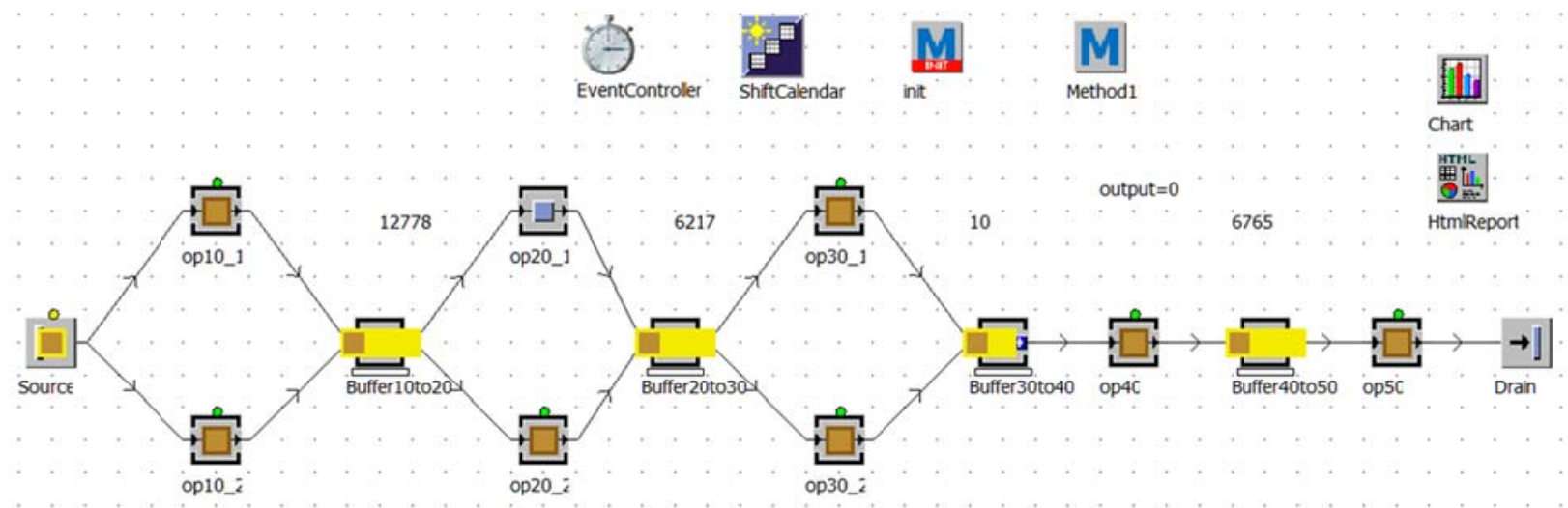

Fig. 3 production line simulation model

The simulation experiment was operated in accordance with the set of production rhythm, process parameters and logistics parameters, and the experiment results were shown in table2. From the table we could see that there was different degree of congestion from OP10 to OP40, and the 
equipment utilization rate was low, which affected the production run smoothly, and also caused staff idle; the processing time of OP30 was the longest, and its equipment utillization rate was high, which belongs to the bottleneck process. Therefore, the overall load of the production line was not balanced enough, which could be improved by adjusting the equipment number or optimizing technical processes. According to the production line balance rate calculation formula: $\eta=\left(\sum_{i=1}^{n} T_{i} / n \times \operatorname{maxT}_{i}\right) \times 100 \%$, we could figure out $\eta_{1}=70.63 \%$. So, it was necessary to optimize the design of the production line.

Table 2 simulation results statistics

\begin{tabular}{|c|c|c|c|}
\hline production processes & working (\%) & waiting (\%) & blocking (\%) \\
\hline OP10 & 41.51 & 0 & 58.49 \\
\hline OP20 & 59.77 & 0 & 40.23 \\
\hline OP30 & 74.4 & 0 & 25.6 \\
\hline OP40 & 60.98 & 0 & 39.02 \\
\hline OP50 & 97.27 & 2.73 & 0 \\
\hline
\end{tabular}

\subsection{Improvement of production line}

Aiming at the problems existed in the original plan, a new method was adopted to concentrate working procedure suitable, which was by using L160LMSA double spindle CNC lathe to merge the original processes OP10-OP30. It could effectively reduce the number of positioning and clamping, guarantee the position accuracy requirement, decrease the turnover and storage area of semi-finished products. The improved processing schedule of bolt was shown in Table3, and the simulation model of the production line was shown in figure4.

Table 3 improved processing schedule

\begin{tabular}{|c|c|c|c|}
\hline production processes & equipment & numbers & processing time (s) \\
\hline OP10 & L160LMSA double spindle CNC lathe & 8 & 139.2 \\
\hline OP20 & RC06 honing machine & 1 & 15 \\
\hline OP30 & HM20 laser marking machine & 1 & 19 \\
\hline
\end{tabular}

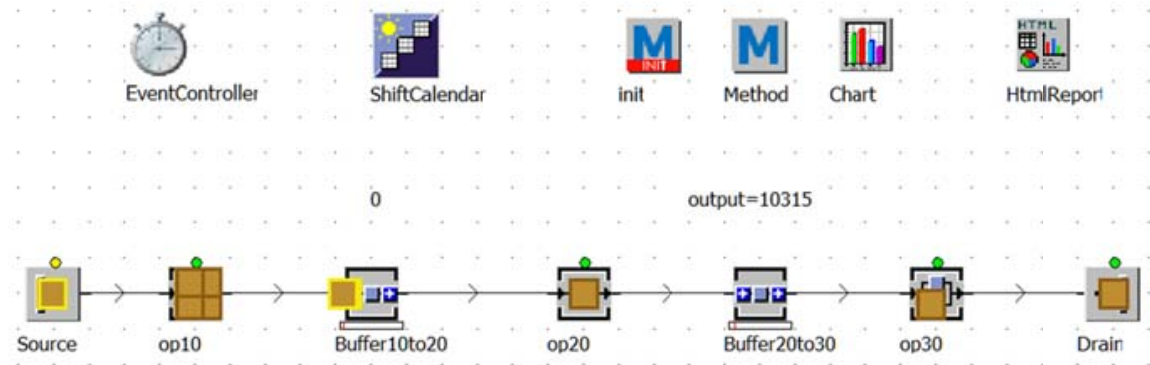

Fig. 4 improved production line simulation model

Running the improved production line simulation model, the experiment results were shown in table4. From the table, the work time of each process was improved significantly, and the efficiency of the production line increased effectively. According to the production line balancing rate formula, we could figure out $\eta_{2}=82.44 \%$, which was much bigger than the initial rate $70.63 \%$. Meanwhile, the production was also increased. 
Table 4 improved simulation results statistics

\begin{tabular}{|c|c|c|c|}
\hline production processes & working (\%) & waiting (\%) & blocking (\%) \\
\hline OP10 & 91.25 & 8.75 & 0 \\
\hline OP20 & 86.21 & 13.79 & 0 \\
\hline OP30 & 89.08 & 10.92 & 0 \\
\hline
\end{tabular}

\section{Conclusions}

The model of bolt automatic production line was established and simulated by the discrete system simulation software Plant Simulation, and also optimized and improved the production line. Therefore, the balance rate of production line and the production efficiency had been improved obviously, and the more reasonable design scheme was determined, which provided technical support for the construction of an actual production line. At the same time, there were still some waits in the operation process; and due to the constraints and changes in the actual production conditions, the production line cannot be completely balanced, so the optimization of automatic production line would be a long lasting process.

\section{Acknowledgements}

This work was supported by National Nature Science Foundation of China (Grant No: 61605205). Corresponding author: ZhaoMing Chen

\section{References}

[1] V Plotnikov, J Vertakova, Manufacturing Industry in Russia: Problems, Status, Prospects, Procedia Economics \& Finance, 2014, 14:499-506.

[2] Z Jin, Automation, Intelligent Manufacturing in China's Die-Forging Industry, Industrial Heating, 2015.

[3] RCP Chung, WH Ip, SL Chan, Impacts of the overheating economy on China's manufacturing industry, The International Journal of Advanced Manufacturing Technology, 2009, 43(11):1133-1143.

[4] Y Sudo, M Matsuda, Autonomous Assembly Process Planning According to the Production Line Configuration (Special Issue on Production Planning and Scheduling), International Journal of Automation Technology, 2015, 9:261-269.

[5] L Li, YL Qian, K Du, YM Yang, Analysis of approximately balanced production lines, International Journal of Production Research, 2015, 54(3):1-18.

[6] ZHOU Jun, LIU Zhanqiang, DENG Jianxin, AI Xing, Virtual Design of Production Line and Its Simulation Application, Manufacturing Technology \& Machine Tool, 2005(1):13-18.

[7] SHAOLi, YANJun-qi, MADong-zhe, ZHONGTing-xiu, Virtual Integrated Design of Production Line, Industrial Engineering and Management, 2000, 5(6):1-4.

[8] Ma Yu-min, Fan Liu-qun, Zhang Hao, Simulation-based planning of production line, Manufacturing Automation,2004,20(10):1107-1109.

[9] GCHR Yazgan, Genetic algorithm parameter optimization using Taguchi method for a flexible manufacturing system scheduling problem, International Journal of Production Research, 2015, 53(3):897-915.

[10] WT Tang, Manufacturing System Research for Multi-variety and Small-batch Based on Plant Simulation, Group Technology \& Production Modernization, 2013.

[11] MM Qi, L Wang, C Yuan, W Gao, eM-Plant-Based Simulation Model for Hot Metal Transportation in Steel Plant, Industrial Engineering Journal, 2010, 13(2):76-81.

[12] S Liu, K Hou, S Jiang, An Analysis on the Automobile Interior Assembly Line Balancing Based on eM-plant, International Conference on Computer Application and System Modeling, 2012, 12(3):104-108. 